\title{
Biogenic ZnO nanoparticles synthesized using $L$. aculeata leaf extract and their antifungal activity against plant fungal pathogens
}

\author{
S NARENDHRAN* and RAJESHWARI SIVARAJ \\ Department of Biotechnology, School of Life Sciences, Karpagam Academy of Higher Education, \\ Eachanari Post, Coimbatore 641 021, India
}

MS received 3 September 2015; accepted 14 September 2015

\begin{abstract}
In this study, Zinc oxide (ZnO) nanoparticles were synthesized using aqueous extract of Lantana aculeata Linn. leaf and assessed their effects on antifungal activity against the plant fungal pathogens. Synthesized nanoparticles were confirmed by ultraviolet-visible spectroscopy, Fourier transform infrared spectrometer, energy-dispersive X-ray spectrometer, X-ray diffractometer, Field-emission scanning electron microscopy, high-resolution transmission electron microscopy. The antifungal activity of $\mathrm{ZnO}$ nanoparticles were determined using the well diffusion method. All the characterization analyses revealed that nanoparticles were highly stable and crystalline in nature. L. aculeata-mediated $\mathrm{ZnO}$ nanoparticles were spherical in shape with an average particle size of $12 \pm 3 \mathrm{~nm}$. Antifungal studies concluded that the maximum zone of inhibition was observed in Aspergillus flavus $(21 \pm 1.0 \mathrm{~mm})$ and Fusarium oxysporum $(19 \pm 1.0 \mathrm{~mm})$ at $100 \mu \mathrm{g} \mathrm{m} \mathrm{m}^{-1}$ concentration. These results clearly indicated the benefits of using $\mathrm{ZnO}$ nanoparticles synthesized using biological methods and shown to have antifungal activities and also that it can be effectively used as antifungal agent in environmental aspect of agricultural development.
\end{abstract}

Keywords. Antifungal activity; FESEM; FTIR; HRTEM; L. aculeata; ZnO nanoparticles.

\section{Introduction}

Nanoparticles have gained increasing importance because of their novel properties, including a large specific surface area and high reaction activity $[1,2]$. Nanoparticles are atomic or molecular aggregates with at least one dimension from 1 to $100 \mathrm{~nm}$ that can drastically modify their physicochemical properties compared with the bulk material [3-5]. Among the metal oxides, nano-zinc oxide $(\mathrm{ZnO})$ exhibits wide band gap $(\sim 3.4 \mathrm{eV})$ and large exciton binding energy (60 meV) and thus it is considered as most promising candidate for nano-optoelectronics, sensors, transistors, nanopiezoelectronics and UV-detection [6]. $\mathrm{ZnO}$ is a II-VI semiconductor material due to its application on solar cells, gas sensors, ceramics and catalysts [7]. ZnO nanoparticles are widely used as an additive into numerous materials and products including paints, cosmetics, plastic and rubber manufacturing, electronics, pharmaceuticals as well as wide applications in agricultural and aquaculture [8].

The synthesis of nanoparticles by conventional physical and chemical methods has some adverse effects like critical conditions of temperature and pressure, expensive and toxic chemicals, long reflux time of reaction, toxic byproducts $[9,10]$. When compared to physical and chemical method, green synthesis of nanoparticles makes use of environmental friendly, non-toxic and safe reagents [11]. In recent times $\mathrm{ZnO}$ nanoparticles have been synthesized using the plant

\footnotetext{
*Author for correspondence (narendhransumathi@gmail.com)
}

extracts of Eichhornia crassipes and assessing its antifungal activity [12]. The effect of temperature on nanoparticle formation also has been investigated and it has been reported that polydisperse particles with a size range of 5-300 nm was obtained at lower temperature while a higher temperature supported the formation of much smaller and spherical particles [13]. Therefore compared to bacteria and fungi, plants are better candidates for the synthesis of nanoparticles [14].

Lantana aculeata (Family: Verbenaceae) is the major exotic weed, spreading rapidly on wastelands, stock poisoning, pose a threat to an environmentally significant area and invasion of desirable pasture. L. aculeata is a heavily branched, scrambling, thicket-forming shrub, usually ranging from 2 to $4 \mathrm{~m}$ in height $[15,16]$. Therefore, nanotechnology is alternate approach for controlling weed plant and management. In the present study, $\mathrm{ZnO}$ nanoparticles were synthesized from L. aculeata leaf extract and the antifungal activity was evaluated using the well diffusion method.

\section{Materials and methods}

\subsection{Materials}

Fresh, healthy and young L. aculeata leaves were collected from Vadavalli region $\left(11.0100^{\circ} \mathrm{N}, 76.9000^{\circ} \mathrm{E}\right)$, Coimbatore, Tamil Nadu, India. The sample was authenticated by Botanical Survey of India, Coimbatore (BSI/SRC/5/23/ 2014-15/Tech/1418). All plant fungal pathogens such as Aspergillus niger (MTCC: 10180), Fusarium oxysporum 
(MTCC: 3326, 3327, 3930) and Penicillium funiculosum (MTCC: 4888) were obtained from Institute of Microbial Technology, Chandigarh, India. All the chemicals were purchased from Sigma-Aldrich Chemicals, India.

\subsection{Preparation of plant extract}

Five grams of fresh leaves were weighed carefully and finely cut. Surfaces of the leaves were washed with running tap water, followed by distilled water. Leaves were ground well in a mortar and pestle using de-ionized water. The mixture of plant extract was heated at $60^{\circ} \mathrm{C}$ for $10 \mathrm{~min}$. After cooling this solution was filtered through filter paper (Whatman no. 42, Maidstone, England) and stored in refrigerator for further studies [17].

\subsection{Synthesis of $\mathrm{ZnO}$ nanoparticles}

Briefly, $0.1 \mathrm{mM}$ zinc nitrate $\left(\mathrm{ZnNO}_{3}\right)$ was prepared with de-ionized water and the volume was made up to $250 \mathrm{ml}$. After complete dissolution of $\mathrm{ZnNO}_{3}$, the flask containing the solution was heated on a water bath at $80^{\circ} \mathrm{C}$ for 5-10 min. Then, $\mathrm{ZnNO}_{3}$ solution was mixed with the plant extract under constant stirring. This mixture of the solution was kept at $100^{\circ} \mathrm{C}$ for $5 \mathrm{~h}$, under vigorous stirring. After this step, a yellow colour precipitate was obtained. This precipitate was discarded through centrifugation $(7000 \mathrm{rpm}$ for $15 \mathrm{~min}$ ). Again, the supernatant was stirred at $150^{\circ} \mathrm{C}$ for $1 \mathrm{~h}$. Finally the solid pale yellow colour precipitate was derived. The precipitate was purified through washing with de-ionized water followed by methanol and air dried. This product was annealed at $400^{\circ} \mathrm{C}$ for $2 \mathrm{~h}$. At the end, colourless powder was obtained [17].

\subsection{Characterization of $\mathrm{ZnO}$ nanoparticles}

Optical properties of synthesized $\mathrm{ZnO}$ nanoparticles were confirmed by ultraviolet-visible spectroscopy (UV-vis) (UV2450 , Shimadzu) in $200-800 \mathrm{~nm}$ wavelength range. The XRD patterns of the synthesized $\mathrm{ZnO}$ nanoparticles were carried out using X-ray diffractometer (Perkin-Elmer spectrum one instrument) $\mathrm{Cu}-\mathrm{K} \alpha$ radiations $(\lambda=0.15406 \mathrm{~nm})$ in $2 \theta$ range from $20^{\circ}$ to $80^{\circ}$. Fourier transform infrared (FT-IR) spectrometer was used for analysis of functional groups in the synthesized $\mathrm{ZnO}$ nanoparticles. FT-IR spectra were recorded in the range $4000-400 \mathrm{~cm}^{-1}$ (PerkinElmer $1725 \mathrm{x}$ ), by the $\mathrm{KBr}$ pellet method. The synthesized $\mathrm{ZnO}$ nanoparticles were analysed for elemental analysis by energy-dispersive X-ray spectrometer (EDX) (RONTEC's EDX system, Model QuanTax 200, Germany). The morphology of the synthesized $\mathrm{ZnO}$ nanoparticles were examined by field-emission scanning electron microscope (FESEM) (Model JSM 7610F, JOEL, USA). The powder sample of $\mathrm{ZnO}$ nanoparticles average size and size distribution were obtained by high-resolution transmission electron microscopy (HRTEM) (JEOL JEM-3100F).

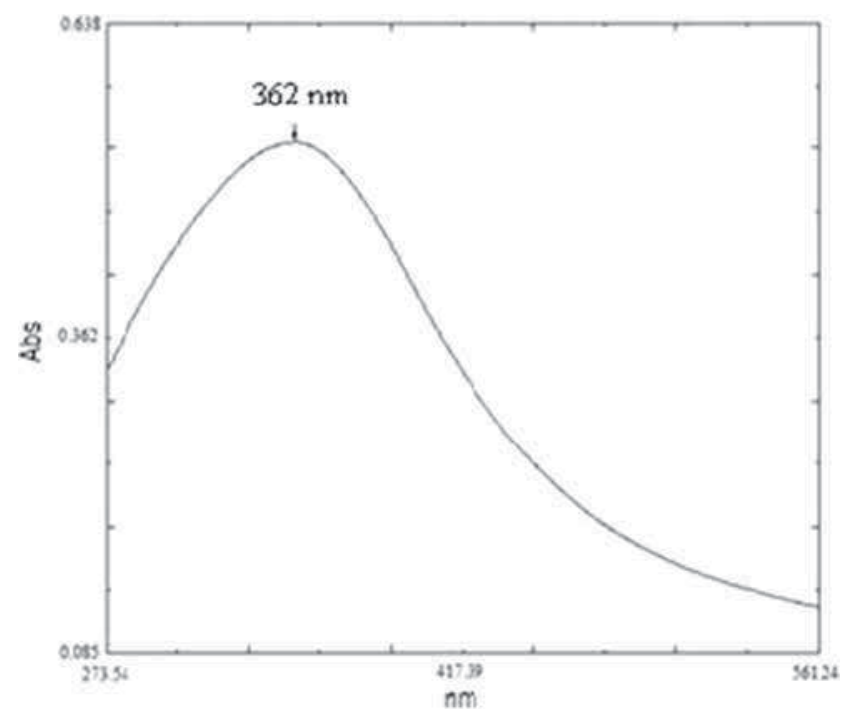

Figure 1. UV spectrum of L. aculeata-mediated $\mathrm{ZnO}$ nanoparticles.

\subsection{Assay for antifungal activity of $\mathrm{ZnO}$ nanoparticles}

Antifungal activities of the synthesized $\mathrm{ZnO}$ nanoparticles were assessed against plant fungal pathogen using a modified Kirby Bauer disc diffusion method [18]. The pathogens were cultured in potato dextrose broth at room temperature on an orbital shaking incubator (Remi, India) at $200 \mathrm{rpm}$. Aliquot of $100 \mu \mathrm{l}$ of culture was swabbed on the potato dextrose agar plates using sterile cotton swab. After that plates were allowed to stand for 10 min to allow for culture absorption. The $5 \mathrm{~mm}$ size wells were punched into the agar with help of sterile gel puncher. Aliquot of $100 \mu \mathrm{l}(25,50,75$ and 100 $\left.\mu \mathrm{g} \mathrm{ml}^{-1}\right)$ of the $\mathrm{ZnO}$ nanoparticles solution and $\left(10 \mu \mathrm{g} \mathrm{ml}^{-1}\right)$ positive control (Amphotricin B) were poured into wells on all plates using micropipette. The plates were incubated in the upside down position at room temperature for $48 \mathrm{~h}$. After incubation period, the zone of inhibition (diameter in millimetre) was measured and the mean values were recorded.

\section{Results and discussion}

\subsection{Synthesis and characterization of $\mathrm{ZnO}$ nanoparticles}

The UV-visible absorption spectra of the monodispersed $\mathrm{ZnO}$ nanoparticles are shown in figure 1 . The absorption spectrum of the synthesized $\mathrm{ZnO}$ recorded the peak at $362 \mathrm{~nm}$ and observed change in colour from brown to pale yellow colour which indicates that the formation of $\mathrm{ZnO}$ nanoparticles. Madhumitha et al [19] reported that the $\mathrm{ZnO}$ nanorods obtained have absorption peak at $364 \mathrm{~nm}$ and the band gap of $\mathrm{ZnO}$ was found to be $3.32 \mathrm{eV}$. Qu et al [20] stated that the $\mathrm{UV}$ absorption spectra for synthesized $\mathrm{ZnO}$ was recorded at $370 \mathrm{~nm}$. Similar results were detected by Rajiv et al [17].

The functional groups in $L$. aculeata Linn. leaves extract and to identify their role in the synthesis of $\mathrm{ZnO}$ 

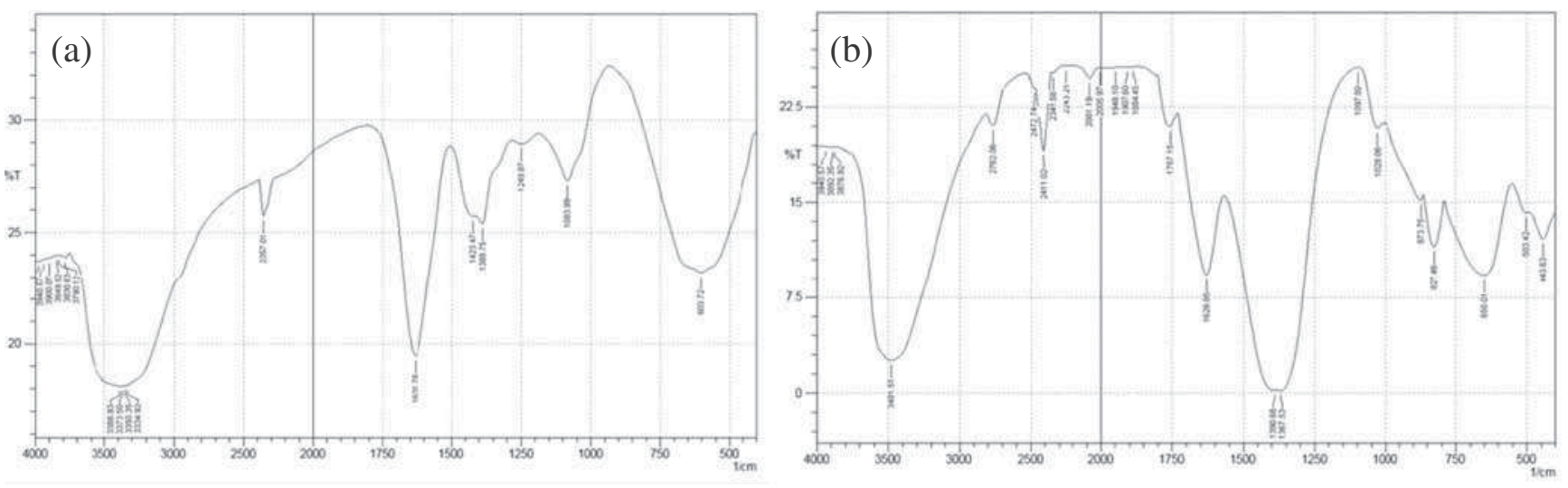

Figure 2. (a) FTIR spectrum of L. aculeata leaves extract and (b) FTIR spectrum of L. aculeata-mediated ZnO nanoparticles.

nanoparticles by FTIR analysis. The peak in the region from 400 to $600 \mathrm{~cm}^{-1}$ is allotted to $\mathrm{ZnO}$ [21]. The IR result (figure 2a) of plant extracts shows the spectrum range at $603.72 \mathrm{~cm}^{-1}$ which indicates the presence of alkyl halides (C-Br stretch), 1083.99, 1249.87 and $1423 \mathrm{~cm}^{-1}$ corresponds to aliphatic amines ( $\mathrm{C}-\mathrm{N}$ stretch) and aromatics (-C-C stretch), $1631.78 \mathrm{~cm}^{-1}$ which indicate primary amines (N-H bend), 3334.92, 3350.35, 3373 and $3388.93 \mathrm{~cm}^{-1}$ show the presence of alcohols, phenols (O-H stretch). This result shows the presence of phytochemicals such as flavones, quinines and organic acids which are responsible for synthesis of nanoparticles [14].

In figure $2 b$, IR spectra of synthesized $\mathrm{ZnO}$ show a high intensity band around $443.63 \mathrm{~cm}^{-1}$ due to the stretching mode of the zinc and oxygen bond [22]. The remaining peak at 1028.06 and $1097.5 \mathrm{~cm}^{-1}$ corresponding to aliphatic amines (C-N stretch) $1757.15 \mathrm{~cm}^{-1}$ indicates carboxylic acids $(\mathrm{C}=\mathrm{O}$ stretch $)$ and $3481.51 \mathrm{~cm}^{-1}$ represents alcohols, phenols (O-H stretch) in L. aculeata extract.

$\mathrm{X}$-ray diffraction was carried out to confirm the phase of $\mathrm{ZnO}$ nanoparticles. The peaks at $2 \theta$ values of $31.78^{\circ}, 34.41^{\circ}$, $36.26^{\circ}, 47.59^{\circ}, 56.59^{\circ}, 62.80^{\circ}, 65.84^{\circ}, 67.96^{\circ}, 68.30^{\circ}$, $72.12^{\circ}$ and $76.53^{\circ}$ corresponded to the crystal planes of (100), (002), (101), (102), (110), (103), (200), (112), (201), (004) and (202) of $\mathrm{ZnO}$ nanoparticles. The diffraction peaks could be referred to spherical phase, which were evaluated with the data from JCPDS card no. 89-7102. The strong and narrow peak denotes that the product has well crystalline nature of particles (figure 3). Similar results were reported by Vanathi et al [12] in which particles were synthesized using E. crassipes leaf extract.

Figure 4 shows the EDX analysis of $\mathrm{ZnO}$ nanoparticles $37.22 \%$ of zinc and $62.78 \%$ of oxygen which confirms the elemental composition of $\mathrm{ZnO}$ nanoparticles. The energydispersive X-ray analysis (EDX) refers strong signal in the zinc region which confirms the formation of $\mathrm{ZnO}$ nanoparticles [23]. The strong signals from the zinc atoms in the nanoparticles recorded and other signals from $\mathrm{C}$ and $\mathrm{O}$ atoms were observed using EDX analysis in Parthenium-mediated $\mathrm{ZnO}$ nanoparticles [17]. The EDX analysis display the

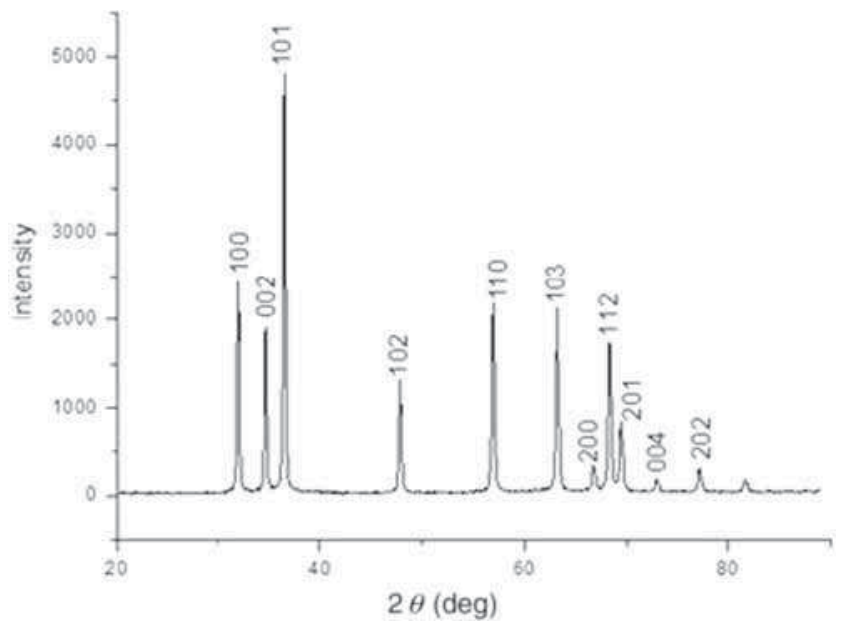

Figure 3. XRD spectrum of L. aculeata-mediated $\mathrm{ZnO}$ nanoparticles.

optical absorption peaks of $\mathrm{ZnO}$ nanoparticles and these absorption peaks were due to the surface plasmon resonance of $\mathrm{ZnO}$ nanoparticles [18]. The FESEM images of $\mathrm{ZnO}$ nanoparticles are shown in figure 5. From the result it is evident that the morphology of $\mathrm{ZnO}$ nanoparticles was spherical in shape and well distributed without aggregation, which is very similar to earlier studies [16]. The size and distribution of the synthesized $\mathrm{ZnO}$ nanoparticles were also confirmed by HRTEM (figure 6). It is evident that the particles average size ranged between $12 \pm 3 \mathrm{~nm}$ and was well dispersed. Similar results were obtained by Vanathi et al [12].

\subsection{Antifungal activity}

The antifungal assay for biologically synthesized $\mathrm{ZnO}$ nanoparticles against the pathogens is shown in figure 7 . Highest zone of inhibition was obtained in A. niger (MTCC: $10180)(21 \pm 1.0 \mathrm{~mm})$ and $F$. oxysporum $(19 \pm 1.0 \mathrm{~mm})$ at a concentration of $100 \mu \mathrm{g} \mathrm{ml}^{-1}$, which is more than positive control (i.e., $12.40 \pm 1.00 \mathrm{~mm}$ ) and which is very similar to 


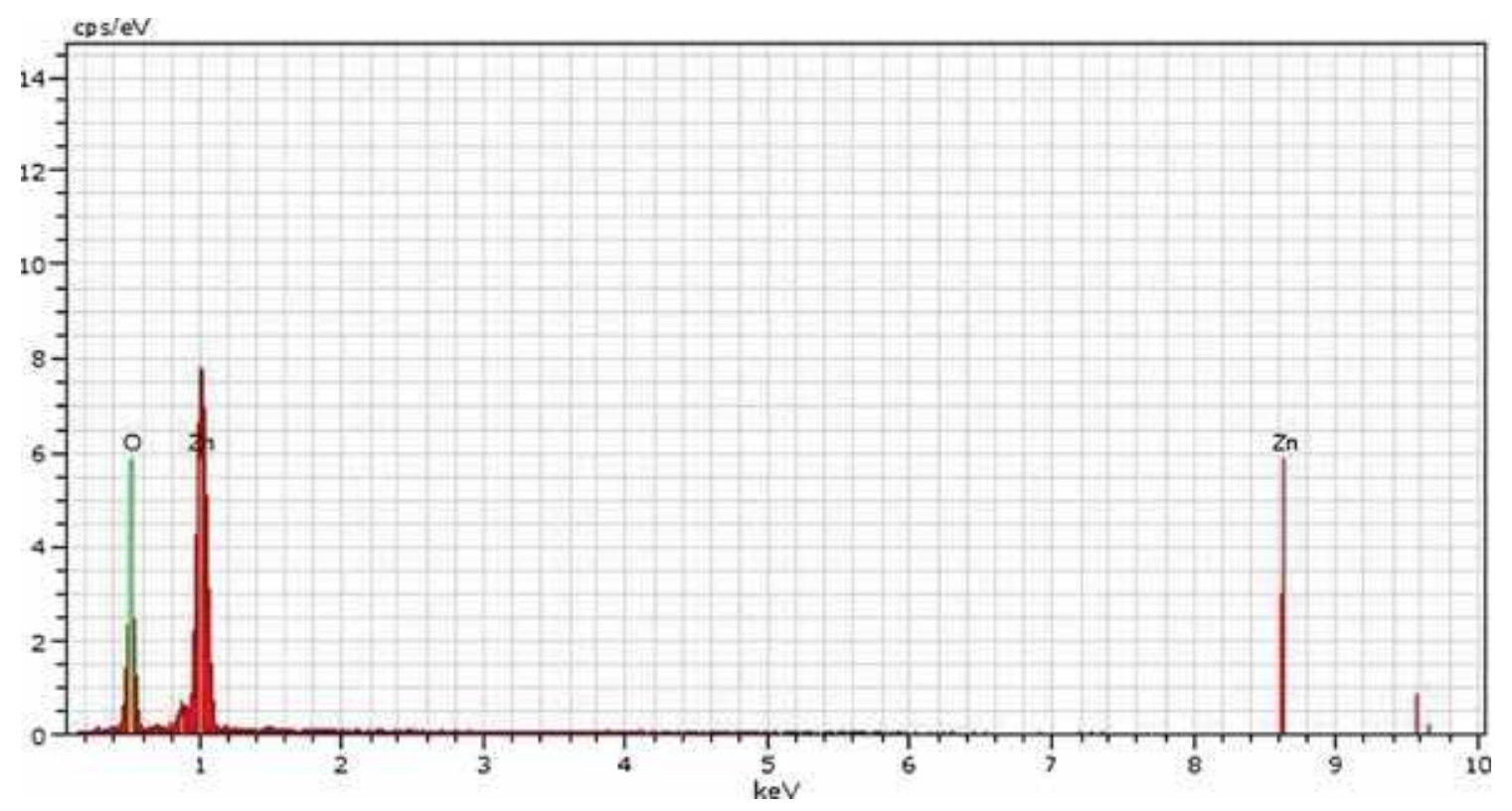

Figure 4. EDX spectrum of L. aculeata-mediated $\mathrm{ZnO}$ nanoparticles.

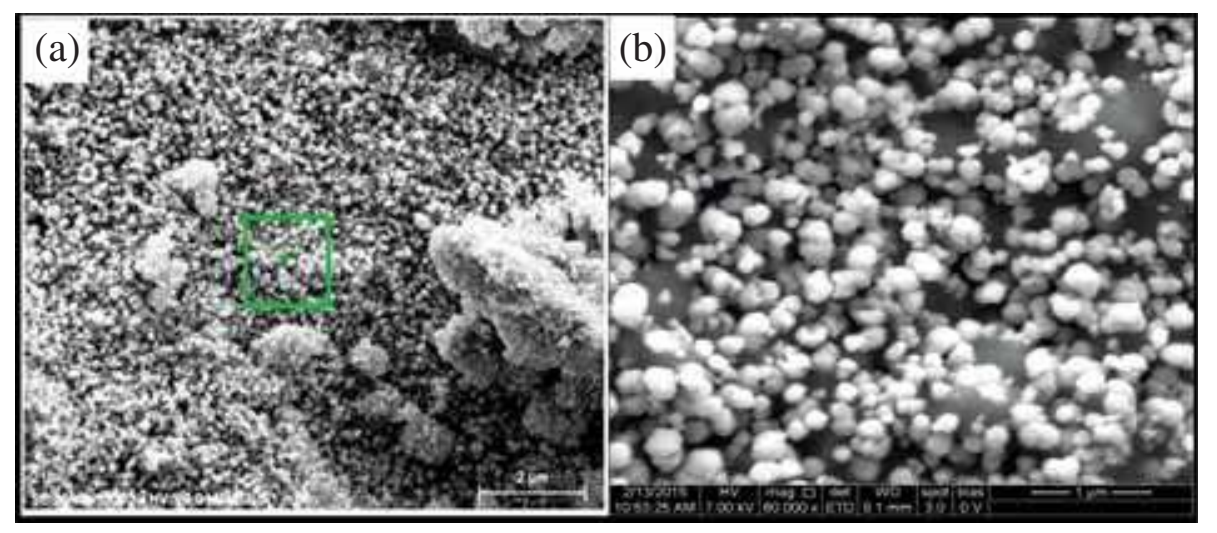

Figure 5. (a and b) FESEM images of L. aculeata-mediated $\mathrm{ZnO}$ nanoparticles.

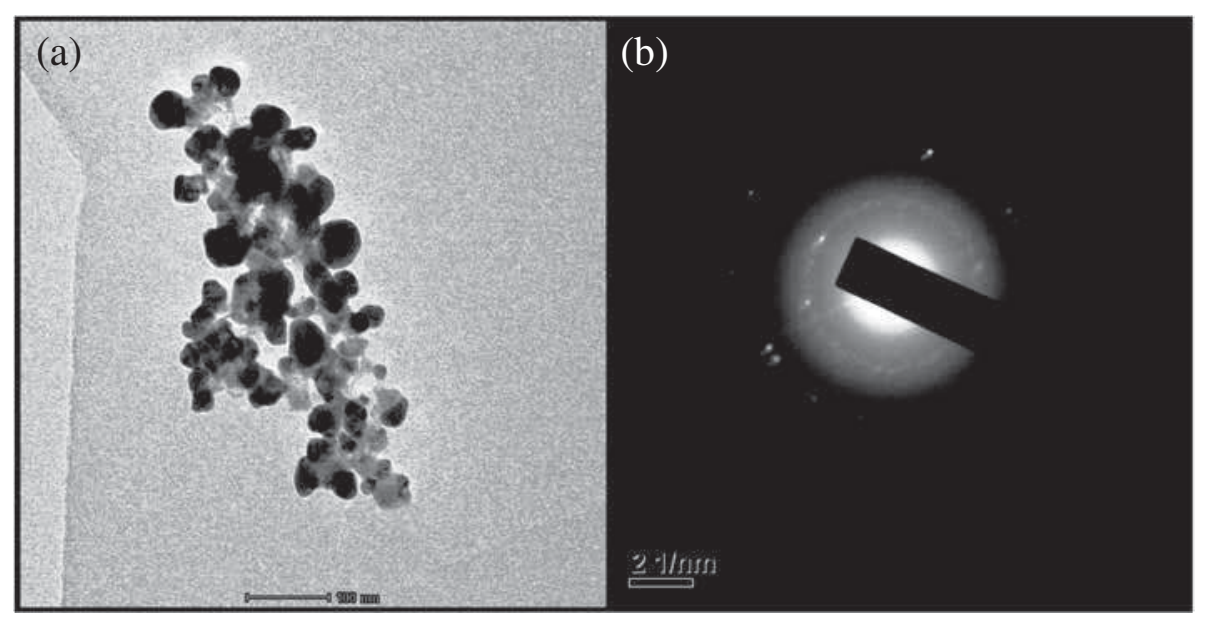

Figure 6. (a) HRTEM images of $L$. aculeata-mediated $\mathrm{ZnO}$ nanoparticles and (b) SAED pattern analysis of $\mathrm{ZnO}$ nanoparticles. 


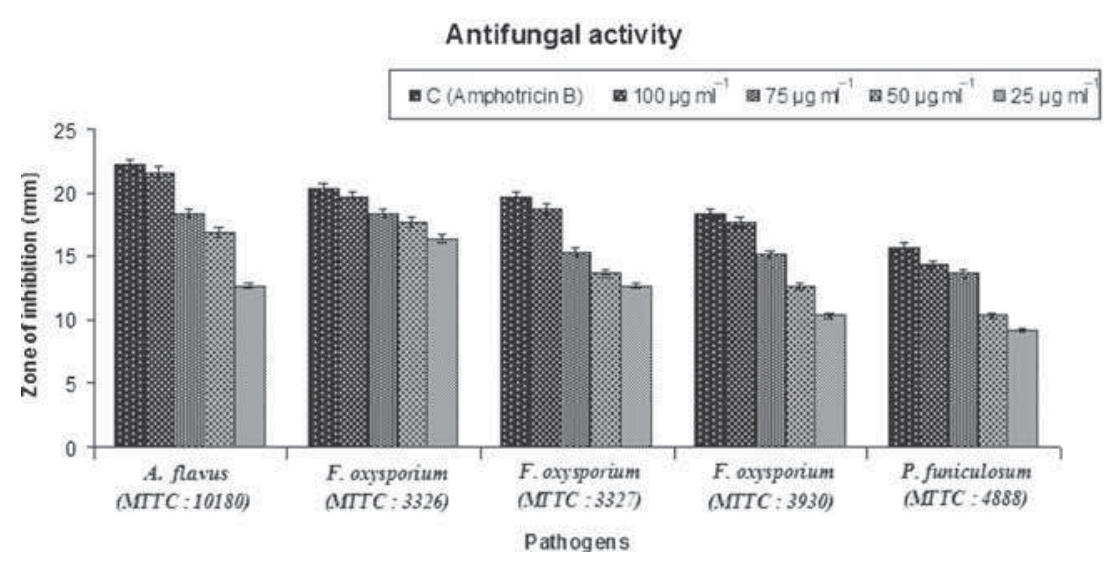

Figure 7. Antifungal activity of L. aculeata-mediated $\mathrm{ZnO}$ nanoparticles.

previous studies against A. flavus $(19 \pm 1.0 \mathrm{~mm})$ [17]. Lowest zone of inhibition was found in F. oxysporum (MTCC: 3930) with a zone diameter of $6.00 \pm 1.00 \mathrm{~mm}$ at $100 \mu \mathrm{g} \mathrm{ml}^{-1}$ concentration of $\mathrm{ZnO}$ nanoparticles. The results confirm that biologically synthesized $\mathrm{ZnO}$ nanoparticles shows excellent antifungal activity.

\section{Conclusion}

The present work, green synthesis of $\mathrm{ZnO}$ nanoparticles from L. aculeata is a green approach, inexpensive, non-toxic and ecofriendly method. All characterization techniques reveal that $\mathrm{ZnO}$ nanoparticles were spherical in shape with an average size of $12 \pm 3 \mathrm{~nm}$. The synthesized $\mathrm{ZnO}$ nanoparticles showed promising antifungal activity against $A$. niger, $F$. oxysporum and P. funiculosum. Therefore, these biogenic $\mathrm{ZnO}$ nanoparticles could be used as a nanopesticide for improving application of agriculture.

\section{Acknowledgement}

We thank the Management of Karpagam Academy of Higher Education, Coimbatore, Tamil Nadu, India, for providing necessary facilities to carry out this work.

\section{References}

[1] Suresh Babu K and Narayanan V 2013 Chem. Sci. Trans. 133

[2] Khorsand Zak A, Razali R, Abd Majid W H and Darroudi M 2011 Int. J. Nanomed. 61399

[3] Ball P 2002 Nanotechnology 1315
[4] Nel A, Xia T, Madler L and Li N 2006 Science 311622

[5] Roco M C 2003 J. Nanopart. Res. 581

[6] Chen Y B, Koh H J, Park K T, Hiraga K, Zhu Z and Yao T 1998 J. Appl. Phys. 343912

[7] Abhulimen U 2005 Mater. Res. Soc. Symp. Proc. 127

[8] Look D C 2001 J. Mat. Sci. Eng. B 80383

[9] Vanaja M, Gnanajobitha G, Paulkumar K, Rajeshkumar S, Malarkodi C and Annadurai G 2013 J. Nanostruct. Chem. 317

[10] Iravani S 2011 Green. Chem. 132638

[11] Mohanpuria P R and Yadav S K 2009 J. Nanopart. Res. 10507

[12] Vanathi P, Rajiv P, Narendhran S, Rajeshwari S, Rahman P K S M and Venckatesh R 2014 Mater. Lett. 13413

[13] Song J Y J and Kim B S 2009 Process Biochem. 441133

[14] Jha A K P and Prasad K 2009 Biochem. Eng. 43303

[15] Ghisalberti E L 2000 Fitoterapia 71467

[16] Rajendiran K, Soumiya D and Sudaroli Sudha J 2014 Int. J. Food Agric. Vet. Sci. 4165

[17] Rajiv P, Rajeshwari S and Venckatesh R 2013 Spectrochim. Acta Part A 112384

[18] Ankanna S and Savithramma N 2011 Asian J. Pharm. Clin. Res. 4137

[19] Madhumitha R, Karthikka P and Navin Kumar S $2014 \mathrm{~J}$. Global Biosci. 3415

[20] Qu J, Luo C and Hou J 2011 Micro. Nano. Lett. 6174

[21] Tas A C, Majewski P J and Aldinger F 2002 J. Am. Ceram. Soc. 851421

[22] Kwon Y J, Kim K H, Lim C S and Shim K B 2002 J. Ceram. Proc. Res. 3146

[23] Vanheusden K, Seager C H, Warren W L, Tallant D R and Voigt J A 1996 Appl. Phys. Lett. 68403 